\title{
The analysis of functional activity of extracellular matrix genes in carotid atherosclerotic plaques
}

\author{
I.A. Goncharova ${ }^{1 *}$, A.V. Markov ${ }^{1}$, A.A. Sleptsov ${ }^{1}$, Y.A. Koroleva ${ }^{1}$, D.V. Sharysh ${ }^{3}$, \\ A.A. Zarubin ${ }^{3}$, N.R. Valiahmetov', E.F. Muslimova ${ }^{2}$, D.S. Panfilov², B.N. Kozlov², \\ S.A. Afanasiev ${ }^{2}$, V.P. Puzyrev ${ }^{1,3}$, M.S. Nasarenko ${ }^{1,3}$ \\ ${ }^{1}$ Research Institute of Medical Genetics, Tomsk, Russia \\ ${ }^{2}$ Research Institute of cardiology, Tomsk, Russia \\ ${ }^{3}$ Siberian State Medical University, Tomsk, Russia \\ *e-mail: irina-goncharova@medgenetics.ru
}

Key words: extracellular matrix genes, carotid artery plaque

Motivation and Aim: arterial sclerotic disease is the reason of cardiovascular diseases progression and the development of severe acute events, which are directly connected with stability of atherosclerotic plaque. Metabolism of extracellular matrix is essential in forming a thick fibrous layer and keeping plaque whole. Our previous researches showed the association between polymorphic variants of genes $A D A M D E C 1, M M P 3, I T G A 4$, $I T G B 5$, TIMP2, which protein products are involved in extracellular matrix metabolism, and the variety of diseases, including myocardial infraction [1, 2]. The aim of this research is to estimate the functional activity of those genes, essential in extracellular matrix metabolism, in the case of carotid artery sclerotic disease.

Methods and Algorithms: Samples of carotid artery plaque (CAP), which were taken from three patients after carotid endarterectomy, were used to perform full genome gene expression analysis. Samples of intact internal mammary arteries (IMA), taken from other patients, were used as control. Gene expression analysis was performed using microchip HumanHT-12 BeadChip (Illumina). Bioinformatics analysis of materials was performed using lumi, limma packages in $\mathrm{R}$ software environment (Bioconductor). Genes with difference of the expression level between sample groups $|\mathrm{FC}| \geq 2$ and $\mathrm{p}_{\mathrm{FDR}}<0.05$, were considered to be differently expressed. Functional annotation of differentially expressed genes was performed in the Web-based GEne SeT AnaLysis Toolkit.

Results: 469 differently expressed transcripts, belonging to 445 genes, were discovered in carotid artery plaque, comparing to intact arteries. Most of overexpressed genes in carotid artery plaque are those, which protein products are involved in extracellular matrix organization (GO:0030198; CD44, COL1A2, COL3A1, COL5A2, FMOD, HAPLN1, ITGA11, ITGAV, SPARC, SPP1, SULF1, TIMP1; $\left.\mathrm{p}_{\mathrm{FDR}}=1.44 \times 10^{-07}\right)$. Genes $A D A M D E C 1$, ITGB5 и TIMP2 are also overexpressed in arteries, damaged by atherosclerosis $\left(\mathrm{p}_{\mathrm{FDR}}=0.018 ; \mathrm{p}_{\mathrm{FDR}}=0.011 ; \mathrm{p}_{\mathrm{FDR}}=0.006\right)$.

Conclusion: Consequently, the functional activity of genes, encoding proteins, are involved in extracellular matrix organization, was increased in carotid artery plaque at the late stages of pathological process.

Acknowledgements: The study was partially supported by the RFBR (16-04-00840).

References

1. Goncharova I.A. et al. (2016) Genes for fibrogenesis in the determination of susceptibility to myocardial infarction. Mol. Biology. 50(1):81-90.

2. Tarasenko N.V. et al. (2017) Association of genes of different functional classes with type 1 diabetes. Russ. J. Genet. 53(8):923-929. 